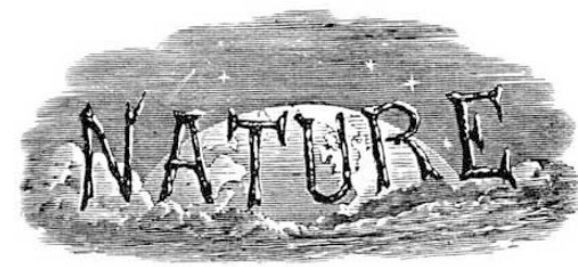

SATURDAY, JUNE 16,1934

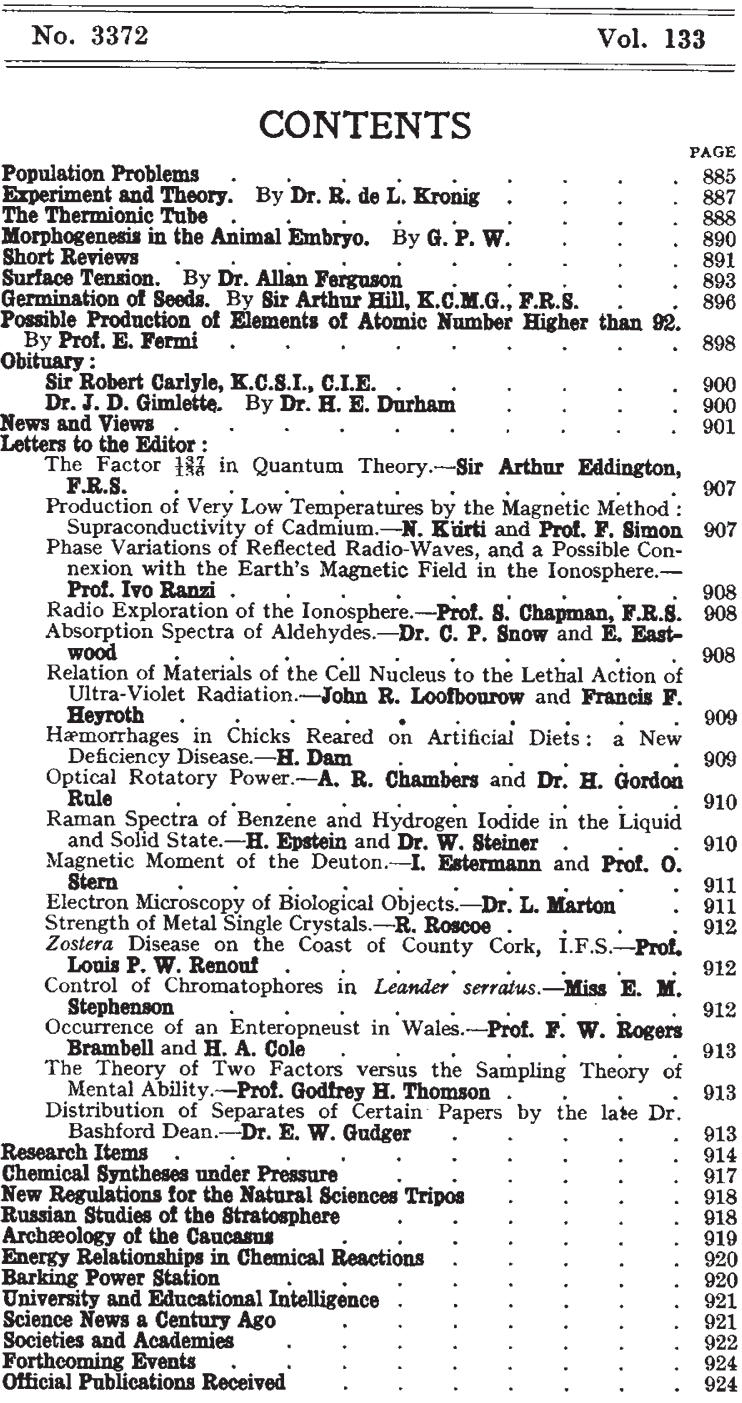

Editorial and Publishing Offices:

MACMILLAN \& CO., LTD.

ST. MARTIN'S STREET, LONDON, W.C.2

Telephone Number: WHITEHALL 8831

Telegraphic Address : PHUSIS, LESQUARE, LONDON

Advertisements should be addressed to

T. G. Scott \& Son, Ltd., 63 Ludgate Hill, London, E.C. 4 Telephone Number : City 4211

\section{Population Problems}

THAT population size and composition exert a profound influence on many of the social, political and economic problems which beset a nation, and that it will be possible to make a fairly accurate forecast of changes in these qualities at different times in the near future, though well established, is not generally understood. Hence addresses such as the recent Huxley Memorial Lecture on the "Restrictive Law of Population" by Prof. Johan Hjort*, and publications such as the newly-issued broadsheet of P.E.P. on "Future British Population" $\dagger$, are to be welcomed and commended to the notice of all those who, for this reason or that, must, now in 1934, take account of the warrantable view that in 1976 the population of Great Britain will be less than, perhaps far less than, 33 million, and that in it the children will be outnumbered by the old. The voice that then will make itself heard will be that of secure senescence, and largely female at that. In 1901 there were 12 million children in Great Britain; in 1951 there may be just over $6 \frac{1}{2}$ million ; the present number of women of sixtyfive years of age and over will be doubled during the next fifty years and will increase by 50 per cent within the next seventeen.

Times have changed, and changed considerably, since the publication of the "Essay on Population". There is no longer any danger of the means of subsistence becoming disproportionate to the number of human individuals dependent on them, for, thanks to developments in the methods of food production, the relation of man to the resources of his environment has been completely reversed. We can produce food of the highest quality, in quantity far in excess of the needs of the sum total of human individuals at present living on the earth; we can force temperature, humidity and light into harmony with our various requirements. Thanks to chemistry, we are becoming more and more freed from our dependence upon animals and plants for commodities that are essential to our well-being, and, furthermore, through developments in reproductive physiology, we are now able deliberately to control the reproductive rate of a human society.

Thus it is that the Malthusian threat of overpopulation has lost much of its force; in fact, in

* The Restrictive Law of Population. By Prof. Johan Hjort (Imperial College of Science and Technology : Huxley Memoria Lecture, 1934.) Pp. 46. (London: Macmillan and Co., Ltd., 1934.) 18. net.

18. Future British Population. Planning: No. 27. May 22, 1934. (P.E.P., 16 Queen Anne's Gate, London, S.W.1.) 
most European countries, and in the United States of America, already in its place there is an increasing fear that the peoples are failing to maintain themselves numerically. In Great Britain the population is already ceasing to increase, and if no further change in the fertility and mortality rates occurs, it can be assumed that a stable age composition in the population will ultimately be reached, and that thereafter the population in each subsequent generation will become progressively, perhaps even alarmingly, diminished. Indeed, it may dwindle away in spite of all improvements in personal and public hygiene which tend to reduce mortality. All the evidence that is available shows that such speculations as these are entirely warrantable.

It becomes a matter of supreme importance, therefore, to those who wish to see the continuance of ourselves as a people, to inquire into the causes of the numerical decline of a population. It is necessary to ask and to answer such a simple question as why it is that people have children at all. The child, which seems to be regarded as a welcome reinforcement by those who speak in the name of the State, as often as not is looked upon by the parent as an inconvenient burden. It seems to be commonly suggested that man, and especially the female of the species, exhibits a definite biological urge toward reproduction. This may be, but the view has no experimental foundation, and its investigation is complicated by the fact that, in our society at least, the mother enjoys certain economic and social advantages. Of all the factors which are recognised as affecting the reproductive rate of a people, it is generally agreed that the one which is mainly responsible for the dwindling of a population is the progressive fall in the average number of children born to each married woman, and it would seem to be established that a people of which the average woman has less than one female offspring is doomed to extinction.

It must remain an unanswered question for the moment as to whether or not it matters very much to the world as a whole and to its further evolution that a particular people, through progressively falling fertility, should disappear. All that we can do is to search for information into the causes that operate in the production of a dwindling population in order to obtain a knowledge of the factors involved, so that this may be made available for incorporation into any programme relating to population size which may be formulated in the future. Manifestly, the problem stated in its simplest terms is that of removing such obstacles to parentage as exist in a particular society.

A great many facts relating to the growth of human populations are already in our possession, but concerning their explanation there is still much disagreement. We know that, in general, the reproductive rate in an industrialised com. munity is lower than that in an agricultural ; that a preponderance of Catholics in a community is commonly associated with a high fertility; that the reproductive rates of people living under different social conditions and belonging to different occupational classes differ more or less widely one from the other. But to find a satisfying explanation for these facts is not simple. If Roman Catholics are remarkable for their high fertility, the Jews, who have a sex ethic that is comparable, show a low reproductive rate. The differential fertility of the different social classes and of the rural community as compared with the urban may be nothing more than evidence that differences in the social environment can yield differences in the expression of certain biological variables.

It has not yet been shown that removal of inequalities in the environment would not produce equality in respect of reproductive rate. Indeed, there are reasons for holding the view that the differential fertility of the social classes is tending to disappear. It has been too easily assumed, perhaps, that a widespread use of contraceptives is in itself a sufficient explanation of a falling birth-rate. It is difficult to accept this statement in view of the fact that legalised abortion and active birth control propaganda in the U.S.S.R. do not seem to affect the growth of a people eager and able to expand.

One thing is certainly true, and that is that a population can only maintain itself if every woman in it bears on the average three children. This of course means that whilst many will bear none, others must bear four and five, and the problem facing those who wish to see our population maintain its present level is that of obtaining in the population a sufficient number of more-thanthree-children families.

It may be assumed that in Great Britain, as in other countries, a low fertility is the result of urbanisation. In the social structure, with its tradition which appeals to the incentive of private profit, and in which there are great inequalities in respect of wealth, with an improvement in the 
standard of living of the people, there have come into being many and varied distractions which can be regarded as alternatives to parenthood. The political emancipation of women and their desire for economic liberty have resulted in competition between women and men in businesses and professions, and motherhood no longer offers a satisfactory career to great numbers of women. The standards of feminine beauty require habits and physical attributes which cannot easily be harmonised with the realities of child-bearing, and undoubtedly one of the most important factors which tend to cause family limitation has been the conferring of an economic advantage upon persons who exhibit a low reproductive rate. There are in Great Britain hundreds of young married couples who are determined not to have children, at least yet awhile, for the simple reason that, conditions of life being as they are, they much prefer to have other things.

The economic barriers to fertility can be overcome by such measures as family endowment, which removes the economic inequality between those who have many children and those who have none, by ruralisation, by giving leave on full pay to women in confinement, but when these things have been done there still will remain the underlying psychological causes of self-imposed sterility. In days gone by, when distractions were fewer, when children were an asset, when the man with a quiver full was most highly respected, when opportunity was plentiful, there being no reason to doubt that the child would enjoy the same opportunities as did his parents, it mattered not that sexual activity was so commonly followed by reproduction. But in these days, it is becoming increasingly common for parentage to cease to be a casual affair and to be a matter of deliberate choice. In the future there will be no such thing as an unwanted child. The problem, in its ultimate analysis, therefore comes to be that of cultivating the wish to have children, and of creating a type of society in which the child shall have a definite function.

If the population of Great Britain dwindles, it will not be because our descendants will be less fecund than were our ancestors, but because they will choose, or will be forced, for economic or other reasons, to limit the number of children entering into an unsatisfactory environment. When the world is fit for children to live in, they will be born; whilst things are as they are, it is perfectly reasonable to limit their numbers.

\section{Experiment and Theory}

Molecular Hydrogen and its Spectrum. By Prof. Owen Willans Richardson. (Yale University: Mrs. Hepsa Ely Silliman Memorial Lectures.) Pp. xiv +343. (New Haven, Conn.: Yale University Press ; London : Oxford University Press, 1934.) 13s. 6d. net.

$\mathrm{A}^{\mathrm{N}}$ NYONE seriously engaged in the pursuit of scientific knowledge, and with a mentality broader than that of the self-sufficient 'research worker', will at one time or another have been confronted with the question as to the importance of his own investigations. Aside from the viewpoint sub specie ceternitatis, from which the playing of the child in the sand and the discovery of the laws of the physical world appear equally important -or unimportant if one prefers - this question will by everyone be admitted to be entirely justified. An answer may perhaps be given in somewhat the following way: the more radical the change in our theoretical notions which an experiment necessitates, the more important the experiment; the larger the group of hitherto unexplained facts to which a theory opens an interpretation, the more important the theory. In these times, when new scientific views penetrate quickly, the frequency with which a scientific publication is quoted by investigators (other than its author) may serve as a quantitative measure of this importance.

Looking at the modern scientific output, one must confess that a good deal of experimental work done to-day is bound to fall into oblivion rather quickly. But while this work still represents a certain amount of conscientious labour and there is, as with a defaulted bond issue, always still a chance that it may become of value, there is no such excuse for the airy castles of speculation of those who forget that the mathematics of the theoretical physicist is a necessary evil and that an accumulation of equations without a physical idea, related in a recognisable way to the empirical reality, does not deserve to be called a theory.

Prof. Richardson is one of the enviable persons who have been able to combine experimental research with theoretical investigation, and through this fortunate circumstance to advance physical science in very diverse directions. The present book, devoted exclusively to the hydrogen molecule and its spectrum, and to a large extent a summary of his own work, illustrates clearly the interaction between experiment and theory. Here is a mass of experimental facts, a spectrum of so involved 